\title{
Admissions and surgery as indicators of hospital functions in Sierra Leone during the west-African Ebola outbreak
}

\author{
Håkon A. Bolkan 1,2,3* D, Alex van Duinen ${ }^{1,2,3}$, Mohammed Samai ${ }^{4,5}$, Donald Alpha Bash-Taqi ${ }^{5,4}$, Ibrahim Gassama ${ }^{4}$,
} Bart Waalewijn ${ }^{3}$, Arne Wibe ${ }^{1,2}$ and Johan von Schreeb ${ }^{6}$

\begin{abstract}
Background: In an attempt to assess the effects of the Ebola viral disease (EVD) on hospital functions in Sierra Leone, the aim of this study was to evaluate changes in provisions of surgery and non-Ebola admissions during the first year of the EVD outbreak.

Methods: All hospitals in Sierra Leone known to perform inpatient surgery were assessed for non-Ebola admissions, volume of surgery, caesarean deliveries and inguinal hernia repairs between January 2014 and May 2015, which was a total of 72 weeks. Accumulated weekly data were gathered from readily available hospital records at bi-weekly visits during the peak of the outbreak from September 2014 to May 2015. The Mann-Whitney U test was used to compare weekly median admissions during the first year of the EVD outbreak, with the 20 weeks before the outbreak, and weekly median volume of surgeries performed during the first year of the EVD outbreak with identical weeks of 2012. The manuscript is prepared according to the STROBE checklist for cross-sectional studies.

Results: Of the 42 hospitals identified, 40 had available data for $94 \%$ (2719/2880) of the weeks. There was a 51\% decrease in weekly median non-Ebola admissions and $41 \%$ fewer weekly median surgeries performed compared with the 20 weeks before the outbreak (admission) and 2012 (volume of surgery). Governmental hospitals experienced a smaller reduction in non-Ebola admissions (45\% versus 60\%) and surgeries (31\% versus 53\%) compared to private nonprofit hospitals. Governmental hospitals realized an increased volume of cesarean deliveries by $45 \%$ during the EVD outbreak, thereby absorbing the $43 \%$ reduction observed in the private non-profit hospitals.

Conclusions: Both non-Ebola admissions and surgeries were severely reduced during the EVD outbreak. In addition to responding to the EVD outbreak, governmental hospitals were able to maintain certain core health systems functions. Volume of surgery is a promising indicator of hospital functions that should be further explored.
\end{abstract}

Keywords: Hospital functioning, Inpatient admissions, Surgery, Ebola viral disease, Sierra Leone

\section{Background}

By the time the World Health Organization (WHO) declared an end to the transmission of the Ebola virus in West-Africa in June 2016, the outbreak had claimed more than 11,000 lives and infected almost 29,000 [1]. During a few months in 2014, the weak and fragile health systems in the three most affected countries,

\footnotetext{
* Correspondence: hakon.a.bolkan@ntnu.no

1 Department of Cancer Research and Molecular Medicine, Norwegian University

of Science and Technology (NTNU), Box 8905, N-7491 Trondheim, Norway

${ }^{2}$ Clinic of Surgery, Trondheim University Hospital, St. Olavs Hospital,

Trondheim, Norway

Full list of author information is available at the end of the article
}

Guinea, Liberia, and Sierra Leone, were overwhelmed with urgent and radically new challenges [2]. The fear of contracting Ebola viral disease (EVD), the deaths of health staff [3], the closure of health facilities, and the disruption of essential health programs $[4,5]$ contributed to reduced health service utilization $[6-10]$ and increased all-causes of mortality [11].

The health system's functions, adaptations, and its consequences for essential health services during the EVD outbreak have been, with a few exceptions $[8,10-13]$, largely based on primary health care services $[5,6,11]$, or estimated by modeling analysis $[3,4,14,15]$. This study

(c) The Author(s). 2018 Open Access This article is distributed under the terms of the Creative Commons Attribution 4.0 International License (http://creativecommons.org/licenses/by/4.0/), which permits unrestricted use, distribution, and reproduction in any medium, provided you give appropriate credit to the original author(s) and the source, provide a link to the Creative Commons license, and indicate if changes were made. The Creative Commons Public Domain Dedication waiver (http://creativecommons.org/publicdomain/zero/1.0/) applies to the data made available in this article, unless otherwise stated. 
complements an assessment of obstetric health care [13] during the EVD outbreak in Sierra Leone and evaluates non-Ebola admissions and the volume of surgeries performed in hospitals. Hospitals, an essential service delivery component of the health care system, are of particular interest during an EVD outbreak because many potential EVD patients are admitted [16], and it is where most EVD-infected health care workers believed they contracted the disease [17]. Collecting and analyzing metrics measuring all aspects of hospital functions have proven challenging even in stable settings in low-income countries [18], and is extremely difficult during a humanitarian emergency such as the EVD outbreak [19]. Therefore, much simpler, yet relevant, approaches need to be applied.

Because of their complexity, provision of surgery signals the presence of the 'staff, stuff, space, and systems' in a hospital [20]. As many of these components are not standalone requirements for surgery, but are rather part of a shared delivery infrastructure that is the basis of hospital functions [21], we assume that provision of surgery might be a relevant indicator of the hospitals' capacity to deliver a broader range of services. In an attempt to assess the EVD's effects on service provisions in hospitals in Sierra Leone, the aim of this study was to evaluate changes in non-Ebola admissions and provision of surgery during the first year of the EVD outbreak.

\section{Methods}

\section{Context}

Sierra Leone is a West African costal country bordering Guinea to the north and east, and Liberia to the south. In 2015 , the population were 7,09 million, divided in 14 districts. The health care system in Sierra Leone is comprised of public, private for-profit, and private non-profit actors and is organized into three tiers of care: peripheral health units, district/regional hospitals, and tertiary hospitals. The governmental is the largest sector where the Ministry of Health and Sanitation (MOHS) formulates policies, mobilizes resources, and monitors and coordinates health care at the central level. Secondary care is delivered in district hospitals typically with more than 100 beds covering a population of about 500,000. There are three regional hospitals which also provide more specialized care. In the capital Freetown, there are furthermore three tertiary hospitals, of which two offer surgical care [22]. Total expenditure on health care was $\$ 590$ million or $\$ 95$ per capita, of which $62 \%$ was private out-of-pocket contributions, $31 \%$ was derived from donor support, and $7 \%$ came from the government. Some $45 \%$ of the total expenditures were spent on hospitals [23]. The country has 0.4 hospital beds per 1000 inhabitants (2006 figures) [24]. Most hospitals operated by private non-profit actors were either faith-based institutions or non-governmental organizations, both with significant international support [25].

\section{Data collection}

All hospitals offering surgery and anesthesia within an operation theatre in Sierra Leone prior to the EVD outbreak were assessed in a collaborative undertaking between the MOHS, the non-governmental organization CapaCare, the Norwegian University of Science and Technology, and the Karolinska Institute in Sweden [7, 13]. Twenty-one community health officers employed in a surgical task sharing training program [26] collected the data using the District Health Information System 2 (DHIS 2) software installed on Huawei Mediapad 7 and is previously described [13]. Weekly accumulated non-Ebola admissions, inguinal hernia repairs, caesarean deliveries, and all surgeries were collected from readily available hospital logbooks. Data were obtained from the first 38 weeks of the year during an initial visit to all hospitals in September 2014, and later during bi-weekly visits until the end of May 2015, altogether totaling 72 weeks. The two most commonly performed surgical operations in Sierra Leone before the EVD outbreak [24], inguinal hernia repair and caesarean delivery, were selected for the study as inguinal hernia repair is a predominantly non-acute surgical intervention performed even in humanitarian emergencies [27], while caesarean delivery is almost exclusively an acute operation in Sierra Leone [28]. Weekly numbers of new confirmed EVD cases were retrieved from the World Health Organization [29].

\section{Definitions}

A surgical operation was defined as any procedure requiring any form of anaesthesia, performed within an operation room and listed in its recording system [30]. Non-Ebola admission was defined as any patient recorded by the hospital administration as being hospitalized, but excluding admissions of suspect, probable or confirmed EVD cases. Hospitals were defined as any health care facilities providing 24-h emergency inpatient care and classified into governmental-, private for-and non-profit [25]. Inpatient admissions, volume of surgery, and caesarean deliveries were used as indicators of hospital functions as described in an Ethiopian national system for monitoring hospital performance [18].

\section{Data analysis and ethical considerations}

Data were analyzed using Statistical Package for the Social Sciences (SPSS), release 23.0 for Macintosh. Median weekly non-Ebola admissions during the first year of the outbreak (week 21 of 2014 to week 20 of 2015) were compared against median weekly admissions in the first 20 weeks of 2014, before the onset of the EVD outbreak in Sierra Leone. To excluded seasonal variations, the surgical volume during the EVD epidemic was compared against similar weeks in 2012 from previously obtained data from the same hospitals [25]. The same data 
sources and approach were applied to obtain the 2012 data as the present study. All comparisons are performed on the weekly medians, for which the Mann-Whitney U test was used to determine if there were differences in admissions or the volume of surgeries performed. The manuscript is prepared according to the STROBE checklist for cross-sectional studies [31]. The study did not require an ethics approval from the local ethics committee, which was confirmed by Office of the Sierra Leone Ethics and Scientific Review Committee. The Director of Research and Non-Communicable Diseases (MS) and the Director of Hospitals and Laboratory Services (DAB-T) of the MOHS approved the study, highlighting that risks for data collectors had to be minimized; hence, data collection needed to be safe, rapid, and cost-effective. Access to the facility registry books was facilitated by the MOHS in which they encouraged all hospitals to share the required data [7]. The main ethical considerations were focused on the safety of the data collectors. As professional health care workers, they had, prior to the hospital visits, received training in infection prevention control and were equipped with personal protective equipment. The registry books were kept in separate rooms from patients; hence, the data collectors were not exposed to symptomatic patients potentially infected with EVD. As public transportation posed the highest risk of accidental EVD exposure, we provided data collectors with a travel allowance to ensure safe movement.

\section{Results}

Out of the 42 hospitals known to perform inpatient surgery in Sierra Leone before the EVD outbreak, two were closed throughout the data collection period and excluded. The 40 hospitals included in this analysis performed $98 \%$ of the national volume of surgeries in hospitals in 2012 [25]. Patients' records were available in 94\% (2719/2880) of the weeks (Tables 1 and 2). All of the 14 districts in the country are represented among the included 40 hospitals (Additional file 1).

\section{Non-EVD admissions}

A total of 91,399 non-Ebola admissions were recorded over 72 weeks; of them, 55,020 were reported during the first year of the outbreak. The 36,379 admissions recorded during the 20 weeks before the EVD outbreak equals an annual rate of 14 admissions per 1000 inhabitants. Before the EVD outbreak in 2014, the governmental hospitals accounted for $57 \%(20,676 / 36,379)$ of the admissions, while the private non-profit and the private for-profit hospitals accounted for 41 and 2\%, respectively. During the EVD outbreak, 63\% of the non-Ebola admissions occurred in governmental hospitals, $36 \%$ in private non-profit and $1 \%$ in private for-profit hospitals. There was an overall $51 \%(P<0.001)$ reduction in the
Table 1 Owner status of the 40 included hospitals

\begin{tabular}{lll}
\hline & Hospitals (\%) & Weeks $^{\mathrm{a}}(\%)$ \\
\hline Total & $40(95)$ & $2719(94)$ \\
Owner & & \\
Governmental & $19(100)$ & $1261(92)$ \\
Privat non-profit & $17(89)$ & $1180(96)$ \\
Private for-profit & $4(100)$ & $278(97)$ \\
Organisational level & & \\
District hospital & $35(95)$ & $2360(94)$ \\
Regional hospital & $3(100)$ & $216(100)$ \\
Tertiary hospital & $2(100)$ & $143(99)$ \\
Location & & $822(88)$ \\
Western area & $13(87)$ & $930(99)$ \\
Northen region & $13(100)$ & $473(94)$ \\
Eastern region & $7(100)$ & $494(98)$ \\
Southern region & $7(100)$ & $1344(93)$ \\
Urban/rural & & $1375(95)$ \\
Urban & & \\
Rural & $20(91)$ & $(100)$
\end{tabular}

${ }^{a}$ Weeks of January 2014 to May 2015 with available data

${ }^{b}$ Settlement with $>50,000$ inhabitants [30]

median weekly non-Ebola admissions during the EVD outbreak compared with before the onset in 2014. Males observed a larger reduction $(55 \%$ versus $50 \%, P<0.001)$ compared with females. The governmental hospitals reduced weekly median admissions by $45 \%$, significantly less $(P<0.001)$ than the $60 \%$ reduction observed at private non-profit hospitals (Fig. 1a).

\section{Surgery}

A total of 20,187 surgical operations were recorded in the 40 hospitals during the study period. Out of those, 8061 were performed the 20 first weeks of 2014, before the onset of EVD, while 12,126 were performed during the first year of the outbreak (Fig. 1b). No differences in the surgical volume was noted comparing the 20 weeks before the EVD outbreak of 2014 with similar institutions and weeks of 2012 (weekly median 407 versus 397, $P=0.552$ ). During the first year of the EVD outbreak, all the 40 hospitals performed $41 \%(P<0.001)$ less weekly median surgeries compared to the 2012 activity (Table 3 ).

The drop in weekly median surgical volume during the EVD outbreak was larger in private non-profit hospitals compared with governmental facilities (53\% versus $31 \%$, $P<0.001$ ) (Fig. 1c). For all hospitals, there was a non-significant $5 \%(P=0.820)$ increase in weekly median caesarean deliveries performed during the EVD outbreak, compared with 2012 (Table 3). While the private non-profit hospitals performed $43 \%(P<0.001)$ fewer weekly median caesarean deliveries, the governmental 
Table 2 Non-EVD Admissions before and during the EVD outbreak

\begin{tabular}{|c|c|c|c|c|}
\hline & Before $E V D^{a}$ & $\mathrm{EVD}^{\mathrm{b}}$ & \multirow{2}{*}{$\begin{array}{l}\text { Change } \\
\%\end{array}$} & \multirow[t]{2}{*}{ Z } \\
\hline & \multicolumn{2}{|c|}{ Weekly median (SD) } & & \\
\hline \multicolumn{5}{|l|}{ All hospitals (40) } \\
\hline Total & $1804(105)$ & $880(465)$ & -51 & $-4.7^{* * * *}$ \\
\hline Female & $1013(69)$ & $511(250)$ & -50 & $-4.7^{* * * *}$ \\
\hline Male & $812(58)$ & $366(218)$ & -55 & $-4.8^{* * * *}$ \\
\hline \multicolumn{5}{|l|}{ Owner } \\
\hline Governmental (19) & $1019(71)$ & $565(236)$ & -45 & $-4.8^{* * * *}$ \\
\hline Privat non-profit (17) & $732(49)$ & $291(220)$ & -60 & $-4.7^{* * * *}$ \\
\hline Private for-profit (4) & $44(7)$ & $0(23)$ & -100 & $-4.6^{* * * *}$ \\
\hline \multicolumn{5}{|l|}{ Organisational level } \\
\hline District hospital (35) & $1210(72)$ & $519(336)$ & -57 & $-4.7^{* * * *}$ \\
\hline Regional hospital (3) & $373(37)$ & $206(105)$ & -45 & $-5.0^{* * * *}$ \\
\hline Tertiary hospital (2) & $213(26)$ & $160(45)$ & -25 & $-4.3^{* * * *}$ \\
\hline \multicolumn{5}{|l|}{ Location } \\
\hline Western area (13) & $556(43)$ & $253(160)$ & -55 & $-4.6^{* * * *}$ \\
\hline Northen region (13) & $631(56)$ & $310(208)$ & -51 & $-4.1^{* * * *}$ \\
\hline Eastern region (7) & $238(36)$ & $154(43)$ & -35 & $-7.0^{* * * *}$ \\
\hline Southern region (7) & $391(40)$ & $154(43)$ & -54 & $-5.2^{* * * *}$ \\
\hline \multicolumn{5}{|l|}{ Urban/rural } \\
\hline Urban (20) & $1037(72)$ & $490(295)$ & -53 & $-4.7^{* * * *}$ \\
\hline Rural (20) & $758(53)$ & $374(185)$ & -51 & $-4.7^{* * * *}$ \\
\hline
\end{tabular}

Week 1-20, 2014

${ }^{\mathrm{b}}$ First 52 weeks of the Ebola outbreak, week 21 of 2014 to week 20 of 2015 ${ }^{\circ}$ Change in weekly medians by comparing identical institutions and weeks ****P $P<0.005$

hospitals increased caesarean deliveries by $45 \%$ ( $P$ $<0.001$ ) during the EVD outbreak.

The decline in surgical volume observed during the EVD outbreak coincided with a change in the types of surgeries performed. The non-acute operation inguinal hernia repair decreased from approximately $20 \%$ of the total volume of surgical procedures before the EVD outbreak to less than $10 \%$ during the peak of the outbreak in late autumn 2014 (Fig. 2a). An opposite trend was observed for caesarean delivery, which represented fewer than $30 \%$ of all surgical operations before the EVD outbreak, yet increased to more than 50\% during the peak of the epidemic towards the end of 2014. The governmental sector increased the proportion of caesarean deliveries both faster and to a larger extent, compared with the private non-profit sector (Fig. 2b). The complete data from the 40 hospitals between January 2014 until week 20 of 2015, including non EVD admissions, caesarean deliveries, inguinal hernia repairs and all surgeries combined is available in Additional file 2 .

\section{Discussion}

This study found a 50\% reduction of hospital admissions, which was the equivalent of 40,000 fewer hospitalizations during the first year of the EVD epidemic in Sierra Leone. A systematic review which evaluated the effects of the West African EVD on healthcare utilization found that the uptake of health service provision (services less available, patients fear and stigma) seemed to be more pronounced than the volume of health care provision [32]. Already before the EVD outbreak, the annual rate of hospitalizations per 1000 inhabitants in Sierra Leone were less than $10 \%$ of the average for Organization for Economic Co-operation and Development (OECD) countries [33]. To what extent this dramatic reduction of hospital care increased mortality is unknown, but its impact is likely considerable, especially in comparison with the 4000 Sierra Leonean EVD deaths [1]. Almost 7500 (41\% weekly median reduction) fewer surgeries performed is also substantial, knowing that only $8 \%$ of surgical needs were met in the country prior to the EVD outbreak [24]. Others have reported reductions in hospital admissions [11, 12] and volume of surgeries [34] during the recent West-African EVD outbreak, but the short observation time for only selected groups of patients from a single or minimal institutions makes those findings less representative. A system wide study like the present seems to be able to revile additional patterns which are not found from assessments of single institutions.

We were surprised that the volume of caesarean deliveries did not change during the EVD outbreak, as this contradicted reports during the outbreak that described an almost complete breakdown of maternal health care [12]. The fact that governmental hospitals managed to increase the volume of caesarean deliveries during the EVD epidemic is impressive, since maternity services are particularly vulnerable to nosocomial EVD infections [35] and obstetric care is known to be exceptionally challenging during an Ebola outbreak [36]. We believe that the urgency of cesarean deliveries which is far more likely to be a lifesaving operation compared to a hernia repairs, were the main reason cesarean deliveries were prioritized before the latter. Regional data and further analysis of normal and caesarean deliveries from the current data set is described by Brolin et al. [13].

Non-Ebola admissions and the volume of surgeries performed during the outbreak saw fewer reductions in governmental hospitals. This might indicate that part of the activities in governmental hospitals functioned better or were given higher prioritization than in the private non-profit hospitals. The absolute and relative increase in the emergency surgical procedure caesarean delivery and the decrease in the non-emergency operation inguinal hernia repairs imply that the governmental 


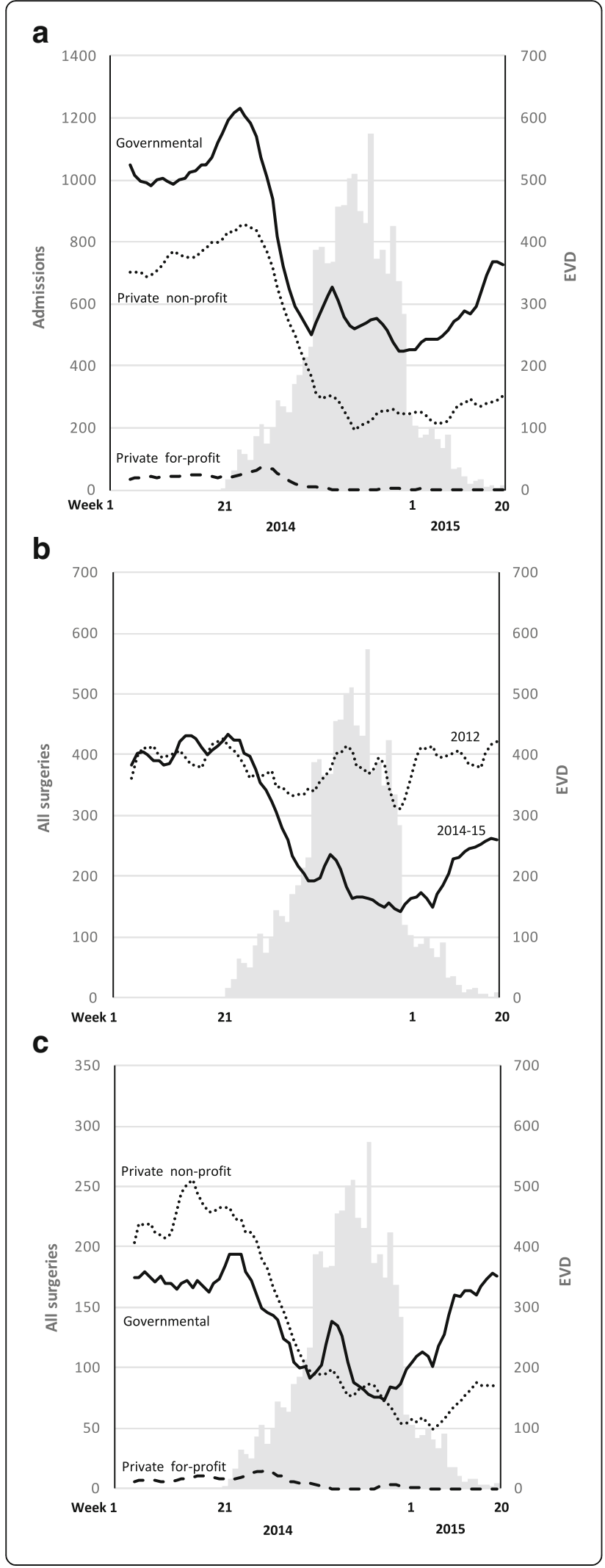

Fig. 1 Weekly admission and surgery before and during the EVD outbreak Legend: The grey bars depict weekly confirmed new Ebola cases until May 17, 2015, which was 52 weeks after the onset of the epidemic in Sierra Leone (All panels). Weekly admissions by hospital owner between January 2014 to week 20 of 2015 (Panel a). Weekly surgical procedures performed between January 2014 and week 20 of 2015 compared to similar facilities and weeks in 2012 (Panel b). Weekly number of surgical procedures by hospital owner in 2014 and the first 20 weeks of 2015 (Panel c)

hospitals adapted adequately in terms of being able to prioritize the most needed surgical services. External factors, such as the establishment of a telephone service for medical emergencies, increased use of ambulances which mostly referred patients to governmental hospitals and the reluctance of traditional birth attendants to assist with deliveries because of the fear of contracting EVD are possible contributions to the increase in caesarean deliveries at governmental hospitals. Resilience refers to the health care system's ability to absorb disturbance, adapt, and respond with the provision of needed services during a crisis [37]. Looking solely at the provision of caesarean delivery in the governmental hospitals during the EVD outbreak, elements of resilience were demonstrated.

The substantial reduction in both admissions and surgeries performed in the largely internationally supported private non-profit hospitals indicates that limited foreign resources were directed towards managing routine health care at the hospital level [38]. Preliminary results were published early in the outbreak to rapidly share the data during the crisis in order to inform the response priorities [7]. Some private hospitals were found to be closed during the peak of the epidemic, while others actively reduced or stopped admissions of non-Ebola patients and focused solely on managing EVD cases. The epidemic caused dramatic additional challenges for the function of hospitals, particularly in the beginning of the outbreak before designated Ebola treatment units were sufficiently established. Revision of the hospital triage systems, increased isolation capacity, new infection prevention measures, and the development of supply chains for EVD-related commodities became imperative for the provision of routine health care services [11]. Difficulties encountered by hospitals in providing safe environments was the most common reason given for closure of private hospitals. On the other hand, governmental facilities remained open for emergency admissions and surgeries throughout the outbreak, despite the challenges encountered in establishing safe hospitals. The courageous undertaking by governmental health care workers to provide essential hospital services was however not accomplished without costs. By May 2015, 6.85\% of the country's 
Table 3 Volume of all surgeries, caesarean deliveries and inguinal hernia repairs in 2012 and during the first year of the EVD outbreak

\begin{tabular}{|c|c|c|c|c|}
\hline & $2012^{a}$ & $E V D^{b}$ & \multirow{2}{*}{$\begin{array}{l}\text { Change }^{c} \\
\%\end{array}$} & \multirow[t]{2}{*}{ Z } \\
\hline & \multicolumn{2}{|c|}{ Weekly median (SD) } & & \\
\hline \multicolumn{5}{|l|}{ All hospitals } \\
\hline All surgeries & $383(33)$ & $227(83)$ & -41 & $-7.1^{* * * *}$ \\
\hline Cesarean deliveries & $87(3)$ & $91(22)$ & 5 & $-0.2, P=0.820$ \\
\hline Inguinal hernia repair & $90(19)$ & $30(21)$ & -67 & $-8.0^{* * * *}$ \\
\hline \multicolumn{5}{|l|}{ Governmental (19) } \\
\hline All surgeries & $182(9)$ & $125(40)$ & -31 & $-6.3^{* * * *}$ \\
\hline Cesarean deliveries & $49(6)$ & $71(16)$ & 45 & $-5.8^{* * * *}$ \\
\hline Inguinal hernia repair & $50(8)$ & $19(12)$ & -62 & $-7.7^{* * * *}$ \\
\hline \multicolumn{5}{|l|}{ Privat non-profit (17) } \\
\hline All surgeries & $188(21)$ & $88(52)$ & -53 & $-6.7^{* * * *}$ \\
\hline Cesarean deliveries & $35(10)$ & $20(10)$ & -43 & $-6.6^{* * * *}$ \\
\hline Inguinal hernia repair & $36(10)$ & $12(10)$ & -67 & $-7.3^{* * * *}$ \\
\hline \multicolumn{5}{|l|}{ Private for-profit (4) } \\
\hline All surgeries & $10(3)$ & $0(5)$ & -100 & $-6.6^{* * * *}$ \\
\hline Cesarean deliveries & $3(1)$ & $0(1)$ & -100 & $-7.0^{* * * *}$ \\
\hline Inguinal hernia repair & $3(1)$ & $0(1)$ & -100 & $-5.0^{* * * *}$ \\
\hline
\end{tabular}

${ }^{\mathrm{a}} 52$ weeks in 2012 [24]

${ }^{b}$ First 52 weeks of the Ebola outbreak, week 21 of 2014 to week 20 of 2015

${ }^{\mathrm{C}}$ Change in weekly medians by comparing identical institutions and weeks **** $P<0.005$

doctors, nurses, and midwives had died of EVD [3], which represented a rate of 100 times higher cumulative incidence compared with the general population [39]. Non-Ebola hospital facilities were associated with $47 \%$ of the EVD infections among health care workers, compared with $11 \%$ for EVD isolation units [17].

The strengths of this study are the broad inclusion of 40 facilities that performed most of the surgeries in the country prior to the EVD outbreak [24], the completeness of the data, the long observation period of 72 weeks, and the utilization of local surgical providers as data collectors. A potential classification bias was that EVD patients early in the outbreak, before designated Ebola treatment units were sufficient, might have been recorded as Non-Ebola admissions. It was not possible to trace or adjust this retrospectively and the consequence of the potential misclassifications is an over reporting of non-Ebola admissions in this material. Obtaining data from readily available logbooks always represents a source of error; however, we have not been able to identify recording habits in the facility registry books that diverge from the actual activity performed. Another potential bias was that non-Ebola admissions during the EVD outbreak were compared against the first 20 weeks of 2014, which do not adjust for seasonal variations in admissions.
The first 20 weeks of the year is dry season, with easier access to hospitals. However, malaria as one of the main causes for severe morbidity potentially in need of hospitalizations are more prevalent during the wet season. How those and other factors influence hospitalizations are not clear. Volume of surgery were however compared against identical weeks of 2012, of which seasonality should not affect the results. Also Brolin et al. [13] compared cesarean deliveries during the EVD outbreak against the first 20 weeks of 2014, which together with a potential selective increase in volume of caesarean deliveries in the governmental hospitals and not in the private hospitals between 2012 and 2014, may explain discrepancies in some of the results presented. This study does not fully capture all hospitals in Sierra Leone, as there are a few highly specialized hospitals that do not perform surgeries, such as a pediatric and a psychiatric hospital.

In the absence of applicable tools to monitor hospital functioning during a disaster in resource-limited settings [18], better uses of readily available routine data is a straightforward and affordable alternative that should be explored further. Evaluating hospital functions based on volume of surgeries is a gross simplification, but seem relevant in this context. An example is the increased provision of the emergency surgical cesarean delivery at the expense of the more 


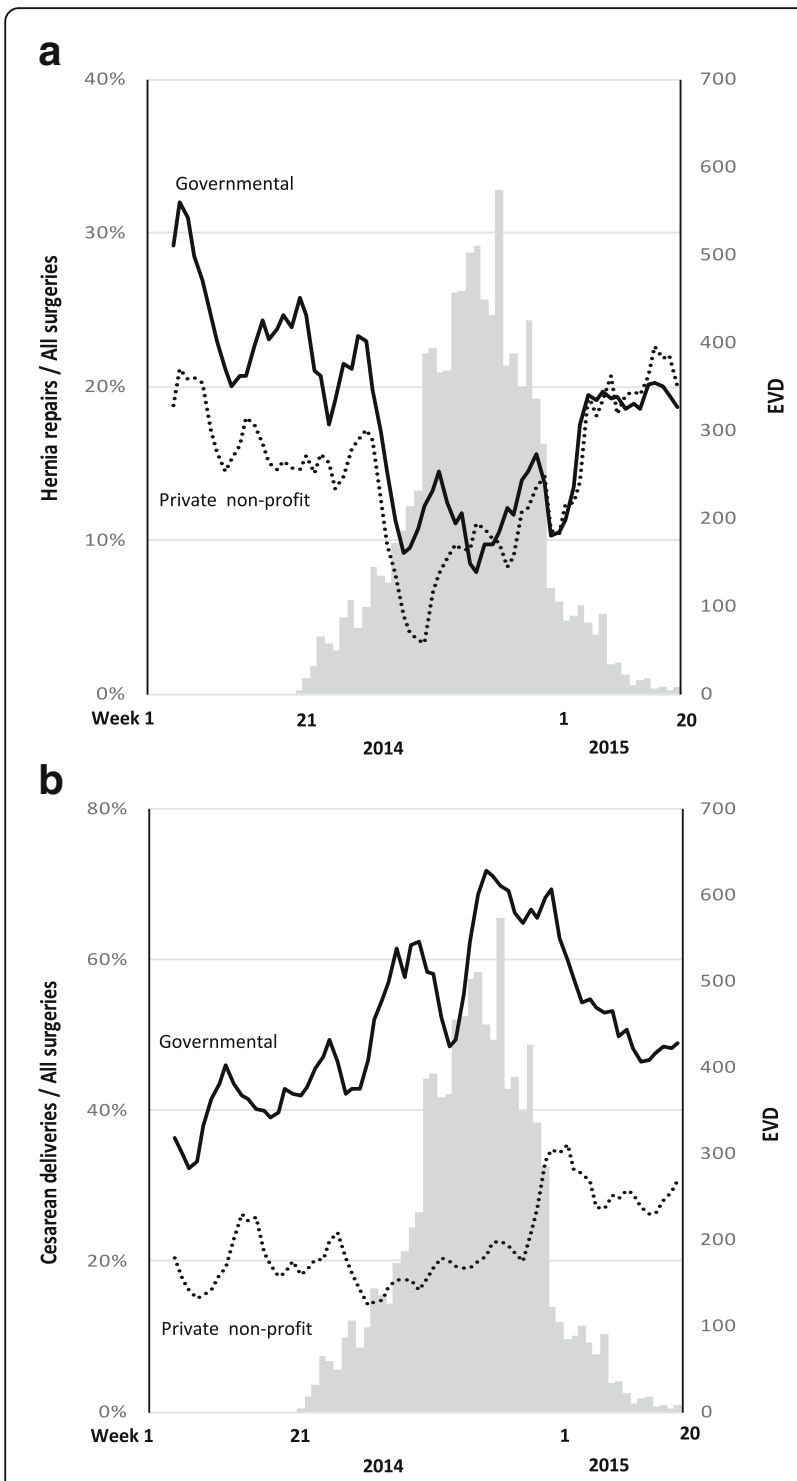

Fig. 2 Proportion of inguinal hernia repairs and caesarean deliveries out of all surgeries performed. Legend: Grey bars are weekly confirmed new Ebola cases until May 17, 2015, 52 weeks after the onset of the epidemic in Sierra Leone (Both panels). Proportion of hernia repairs out of all surgeries performed for governmental and private non-profit hospitals before and during the EVD outbreak (Panel a). Proportion of caesarean deliveries out of all surgeries performed for governmental and private non-profit hospitals before and during the EVD outbreak (Panel b)

non-emergent hernia repairs which indicates that elements of resiliency was observed. Surgery is one of the most advanced and resource demanding services offered at hospitals in general and requires a functioning infrastructure and a broad range of support functions [20, 21], such as laboratory-, radiology-, anesthesia-, together with pre- and post-operative services. Further studies are needed to explore the relationship between provision of surgery and the hospital's capacity to deliver other essential health care services, as well as the relevance of surgical volume as an indicator of hospital functions in resource constrained areas.

\section{Conclusions}

Admissions and volume of surgery were less reduced during the EVD outbreak in governmental hospitals compared with private hospitals. In a crisis context where more comprehensive healthcare system information tools are not feasible to implement, available routine data can be a straightforward alternative, and volume of surgery is a promising indicator of hospital functions that should be further explored. The governmental hospitals' ability to absorb the reduction of cesarean deliveries in the private hospitals can be seen as encouraging seeds of healthcare system resilience worth cultivating in the post-Ebola recovery phase.

\section{Additional files}

Additional file 1: List of included hospitals. (PDF $15 \mathrm{~kb}$ )

Additional file 2: Raw data. (XLSX $69 \mathrm{~kb}$ )

\section{Abbreviations}

EVD: Ebola viral disease; MOHS: Ministry of Health and Sanitation; OECD: Organization for Economic Co-operation and Development; SPSS: Statistical Package for the Social Sciences; WHO: World Health Organization

\section{Acknowledgements}

We thank all the data collectors for obtaining the necessary data for this study; Amara Conteh, Emmanuel Tommy, Samuel Batty, Alpha Mohamed Samura, Amadu Jawara, Dauda Lahai, Alpha Marah, Mohamed Nuyabah, Mohamed Kamara, Alieu Faylulu Mansaray, Nyayia Salamatu Saidu, Joseph M. Bassie, Mohamed M. Dauda, Ibrahim Fortune, Sulaiman P Kamara, Solomon S Samura, Hassan P. Vandy, Ishmael Kamara Dumbuya, Lawrance Teteh Kargbo, David S Kain, Allen Bockarie Mansaray, Sheku Conteh, Seibatu Sia Kemoh, Sei Bill Coleman.

Funding

This survey was funded by the Wallenberg Foundation, CapaCare and the Norwegian University of Science and Technology. The funders had no role in the design, data collection and analysis, decision to publish, or preparation of the manuscript.

\section{Availability of data and materials}

All data generated or analyzed during this study are included in this published article and its supplementary information files.

\section{Authors' contributions}

$H A B, A v D, B W, M S, D A B-T$, JvS made substantial contributions to conception and design. $H A B, A v D, B W, M S, D A B-T, I G$ and JvS participated in acquisition of data. $H A B, A v D, B W, A W$ and JvS analyzed the data. All authors interpreted the data. $H A B, A v D, A W$ and JvS drafted the manuscript. All authors revised the manuscript critically for intellectual content and gave final approval of the version to be published. All authors take responsibility for the content and ensure accuracy of any part of the work.

Ethics approval and consent to participate

This study did not require an ethics approval from the local ethics committee, which has been confirmed by Office of the Sierra Leone Ethics and Scientific Review Committee.

Consent for publication

All authors have consented for publication. 


\section{Competing interests}

The authors declare that they have no competing interests.

\section{Publisher's Note}

Springer Nature remains neutral with regard to jurisdictional claims in published maps and institutional affiliations.

\section{Author details}

'Department of Cancer Research and Molecular Medicine, Norwegian University of Science and Technology (NTNU), Box 8905, N-7491 Trondheim, Norway. ${ }^{2}$ Clinic of Surgery, Trondheim University Hospital, St. Olavs Hospital, Trondheim, Norway. ${ }^{3}$ CapaCare, Norway, Sierra Leone. ${ }^{4}$ College of Medicine and Allied Health Sciences, University of Sierra Leone, Freetown, Sierra Leone. ${ }^{5}$ Ministry of Health and Sanitation, Freetown, Sierra Leone. ${ }^{6}$ Health System and Policy Research Group, Karolinska Institutet, SE-171 77 Stockholm, Sweden.

Received: 23 August 2016 Accepted: 30 October 2018

Published online: 09 November 2018

\section{References}

1. World Healt Organization. Situation report ebola virus disease June 10, 2016 http://apps.who.int/iris/bitstream/10665/208883/1/ebolasitrep_10Jun2016 eng.pdf?ua=1. Accessed $1 \mathrm{Jul} 2016$.

2. Gostin LO, Friedman EA. A retrospective and prospective analysis of the west African Ebola virus disease epidemic: robust national health systems at the foundation and an empowered $\mathrm{WHO}$ at the apex. Lancet. 2015;385:1902-9.

3. Evans DK, Goldstein M, Popova A. Health-care worker mortality and the legacy of the Ebola epidemic. Lancet Glob Health. 2015;3:e439-40.

4. Walker PG, White MT, Griffin JT, Reynolds A, Ferguson NM, Ghani AC. Malaria morbidity and mortality in Ebola-affected countries caused by decreased health-care capacity, and the potential effect of mitigation strategies: a modelling analysis. Lancet Infect Dis. 2015;15:825-32.

5. Loubet P, Mabileau G, Baysah M, Nuta C, Taylor M, Jusu H, et al. Likely effect of the 2014 Ebola epidemic on HIV care in Liberia. AIDS. 2015:29:2347-51.

6. UNICEF. Sierra Leone Health Facility Survey 2014: Assessing the impact of the EVD outbreak on health systems in Sierra Leone, 2014. http://www. unicef.org/emergencies/ebola/files/SL_Health_Facility_Survey_2014Dec3.pdf. Accessed 1 Jul 2016.

7. Bolkan HA, Bash-Taqi DA, Samai M, Gerdin M, von Schreeb J. Ebola and indirect effects on health service function in Sierra Leone. PLoS currents. 2014. https://doi.org/10.1371/currents.outbreaks. 0307d588df619f9c9447f8ead5b72b2d.

8. Barden-O'Fallon J, Barry MA, Brodish P, Hazerjian J. Rapid assessment of Ebola-related implications for reproductive, maternal, newborn and child health service delivery and utilization in Guinea. PLoS currents. 2015. https:// doi.org/10.1371/currents.outbreaks.0b0ba06009dd091bc39ddb3c6d7b0826.

9. Leuenberger D, Hebelamou J, Strahm S, De Rekeneire N, Balestre E, Wandeler $\mathrm{G}$, et al. Impact of the Ebola epidemic on general and HIV care in Macenta, Forest Guinea, 2014. AIDS. 2015;29:1883-7.

10. Plucinski MM, Guilavogui T, Sidikiba S, Diakite N, Diakite S, Dioubate M, et al. Effect of the Ebola-virus-disease epidemic on malaria case management in Guinea, 2014: a cross-sectional survey of health facilities. Lancet Infect Dis. 2015; 15:1017-23.

11. Elston JW, Moosa AJ, Moses F, Walker G, Dotta N, Waldman RJ, et al. Impact of the Ebola outbreak on health systems and population health in Sierra Leone. J Public Health (Oxf). 2015. https://doi.org/10.1093/pubmed/fdv158.

12. Delamou A, Hammonds RM, Caluwaerts S, Utz B, Delvaux T. Ebola in Africa: beyond epidemics, reproductive health in crisis. Lancet. 2014;384:2105.

13. Brolin Ribacke KJ, van Duinen AJ, Nordenstedt H, Hoijer J, Molnes R, Froseth TW, et al. The impact of the West Africa Ebola outbreak on obstetric health Care in Sierra Leone. PLoS One. 2016. https://doi.org/ 10.1371/journal.pone.0150080.

14. Parpia AS, Ndeffo-Mbah ML, Wenzel NS, Galvani AP. Effects of response to 2014-2015 Ebola outbreak on deaths from malaria, HIV/AIDS, and tuberculosis, West Africa. Emerg Infect Dis. 2016;22:433-41.

15. Takahashi S, Metcalf CJ, Ferrari MJ, Moss WJ, Truelove SA, Tatem AJ, et al. Reduced vaccination and the risk of measles and other childhood infections post-Ebola. Science. 2015;347:1240-2.
16. Hall RC, Hall RC, Chapman MJ. The 1995 Kikwit Ebola outbreak: lessons hospitals and physicians can apply to future viral epidemics. Gen Hosp Psychiatry. 2008;30:446-52.

17. Olu O, Kargbo B, Kamara S, Wurie AH, Amone J, Ganda L, et al. Epidemiology of Ebola virus disease transmission among health care workers in Sierra Leone, may to December 2014: a retrospective descriptive study. BMC Infect Dis. 2015;15:416.

18. McNatt Z, Linnander E, Endeshaw A, Tatek D, Conteh D, Bradley EH. A national system for monitoring the performance of hospitals in Ethiopia. Bull World Health Organ. 2015;93:719-26.

19. Bayram JD, Kysia R, Kirsch TD. Disaster metrics: a proposed quantitative assessment tool in complex humanitarian emergencies - the public health impact severity scale (PHISS). PLoS currents. 2012;4: e4f7b4bab0d1a3.

20. Meara JG, Leather AJ, Hagander L, Alkire BC, Alonso N, Ameh EA, et al, Global surgery 2030: evidence and solutions for achieving health, welfare, and economic development. Lancet. 2015;386:569-624.

21. Kim JY, Farmer P, Porter ME. Redefining global health-care delivery. Lancet. 2013;382:1060-9.

22. Ministry of Health and Sanitation. Sierra Leone Basic Package of Essential Health Services 2015-2020, 2015 https:/mohs2017.files.wordpress.com/ 2017/06/gosl_2015_basic-package-of-essential-health-services-2015-2020. pdf. Accessed 1 July 2016.

23. Ministry of Health and sanitation. Sierra Leone National Health Accounts 20132015 https://mohs2017.files.wordpress.com/2017/03/nha-2013.pdf. Accessed 26 May 2017

24. The World Bank. Data Catalog 2017. http://data.worldbank.org/indicator/SH. MED.BEDS.ZS?locations=SL. Accessed 26 May 2017.

25. Bolkan HA, Von Schreeb J, Samai MM, Bash-Taqi DA, Kamara TB, Salvesen O, et al. Met and unmet needs for surgery in Sierra Leone: a comprehensive, retrospective, countrywide survey from all health care facilities performing operations in 2012. Surgery. 2015;157:992-1001.

26. Bolkan HA, van Duinen A, Waalewijn B, Elhassein M, Kamara TB, Deen GF, et al. Safety, productivity and predicted contribution of a surgical task-sharing programme in Sierra Leone. BJS. 2017. https://doi.org/10. 1002/bjs.10552.

27. Stewart B, Wong E, Papillon-Smith J, Trelles Centurion MA, Dominguez L, Ao $S$, et al. An analysis of cesarean section and emergency hernia ratios as markers of surgical capacity in low-income countries affected by humanitarian emergencies from 2008-2014 at Medecins sans Frontieres operations Centre Brussels projects. PLoS currents. 2015. https://doi.org/10. 1371/currents.dis.5e30807568eaad09a3e23282ddb41da6.

28. Chu K, Cortier H, Maldonado F, Mashant T, Ford N, Trelles M. Cesarean section rates and indications in sub-Saharan Africa: a multi-country study from Medecins sans Frontieres. PLoS One. 2012;7:e44484.

29. World Health Organization. Ebola data and statistics 2016. http://apps. who.int/gho/data/node.ebola-sitrep.quick-downloads?lang=en. Accessed 1 Jul 2016.

30. Weiser TG, Regenbogen SE, Thompson KD, Haynes AB, Lipsitz SR, Berry WR, et al. An estimation of the global volume of surgery: a modelling strategy based on available data. Lancet. 2008;372(9633):139-44.

31. von Elm E, Altman DG, Egger M, Pocock SJ, Gøtzsche PC, Vandenbroucke JP, STROBE Initiative. The strengthening the reporting of observational studies in epidemiology (STROBE)statement: guidelines for reporting observational studies. Bull World Health Organ. 2007;85: 867-72.

32. Brolin Ribacke KJ, Saulnier DD, Eriksson A, von Schreeb J. Effects of the West Africa Ebola virus disease on health-care utilization - a systematic review. Front Public Health. 2016:4:222

33. Organisation for Economic Co-operation and Development (OECD). Hospital discharges: OECD Publishing, 2015. http://www.oecd-ilibrary.org/socialissues-migration-health/health-at-a-glance-2015/hospital-discharges_health_ glance-2015-33-en. Accessed 1 Jul 2016

34. Bundu I, Patel A, Mansaray A, Kamara TB, Hunt LM. Surgery in the time of Ebola: how events impacted on a single surgical institution in Sierra Leone. J R Army Med Corps. 2016. https://doi.org/10.1136/jramc-2015000582.

35. Dunn AC, Walker TA, Redd J, Sugerman D, McFadden J, Singh T, et al. Nosocomial transmission of Ebola virus disease on pediatric and maternity wards: Bombali and Tonkolili, Sierra Leone, 2014. Am J Infect Control. 2016;44:269-72. 
36. Akerlund E, Prescott J, Tampellini L. Shedding of Ebola virus in an asymptomatic pregnant woman. N Engl J Med. 2015;372:2467-9.

37. Kruk ME, Myers M, Varpilah ST, Dahn BT. What is a resilient health system? Lessons from Ebola. Lancet. 2015;385:1910-2.

38. Kieny MP, Evans DB, Schmets G, Kadandale S. Health-system resilience: reflections on the Ebola crisis in western Africa. Bull World Health Organ. 2014;92:850.

39. Kilmarx PH, Clarke KR, Dietz PM, Hamel MJ, Husain F, McFadden JD, et al. Ebola virus disease in health care workers--Sierra Leone, 2014. MMWR Morb Mortal Wkly Rep. 2014;63:1168-71.

Ready to submit your research? Choose BMC and benefit from:

- fast, convenient online submission

- thorough peer review by experienced researchers in your field

- rapid publication on acceptance

- support for research data, including large and complex data types

- gold Open Access which fosters wider collaboration and increased citations

- maximum visibility for your research: over $100 \mathrm{M}$ website views per year

At $\mathrm{BMC}$, research is always in progress.

Learn more biomedcentral.com/submissions 